\title{
BMJ Open Pattern of corneal astigmatism induced by primary pterygium in patients with cataract in a secondary hospital in Southern China: a cross-sectional study
}

\author{
Guihua Xu, ${ }^{1,2,3}$ Wei Qi, ${ }^{4}$ Yijun Hu (D) ${ }^{1,3}$
}

To cite: Xu G, Qi W, Hu Y. Pattern of corneal astigmatism induced by primary pterygium in patients with cataract in a secondary hospital in Southern China: a crosssectional study. BMJ Open 2020;10:e034219. doi:10.1136/ bmjopen-2019-034219

- Prepublication history for this paper is available online. To view these files, please visit the journal online (http://dx.doi. org/10.1136/bmjopen-2019034219).

Received 12 September 2019 Revised 06 November 2019 Accepted 07 January 2020

Check for updates

(c) Author(s) (or their employer(s)) 2020. Re-use permitted under CC BY-NC. No commercial re-use. See rights and permissions. Published by BMJ.

${ }^{1}$ Aier Institute of Refractive Surgery, Refractive Surgery Center, Guangzhou Aier Eye Hospital, Guangzhou, China ${ }^{2}$ Department of Ophthalmology, Huizhou Municipal Central Hospital, Huizhou, China ${ }^{3}$ Aier School of Ophthalmology, Central South University,

Changsha, China

${ }^{4}$ Shanwei Eye Hospital, Shanwei, China

Correspondence to

Dr Yijun Hu;

huyijun2014@163.com

\section{ABSTRACT}

Objectives To review the pattern of primary pterygiuminduced corneal astigmatism in patients with cataract in a southern Chinese population.

Design Clinic-based cross-sectional retrospective study. Setting A secondary hospital at southern China.

Participants A group of 1689 eyes with primary pterygium (PT group) and the other group of 4062 eyes without pterygium (NPT group) were included.

Main outcome measures Corneal power was measured by an autokeratorefractometer. Corneal astigmatism was calculated as the difference in corneal power between the steepest and flattest meridians. Distribution of corneal astigmatism was compared between eyes with pterygium and eyes without pterygium.

Results Distribution of corneal astigmatism was different between PT group (skewness=2.548, kurtosis=8.237) and NPT group (skewness=2.778, kurtosis=15.52). Mean corneal astigmatism was significantly higher in the PT group $(1.62 \pm 1.49 \mathrm{D})$ compared with the NPT group $(1.17 \pm 0.89 \mathrm{D}$, $\mathrm{p}<0.0001)$. The prevalence of corneal astigmatism $>1 \mathrm{D}$ (PT 52.3\%, NPT 40.9\%, p<0.0001), >2D (PT 22.4\%, NPT $10.6 \%, p<0.0001$ ) or $>3$ D (PT 10.5\%, NPT 3.2\%, p<0.0001) was significantly higher in the PT group compared with the NPT group. Eyes in the PT group had significantly higher corneal astigmatism than the NPT group in almost every age group (all $p<0.05$ ), with the exception of patients $\geq 90$ years. Moreover, eyes in the PT group had significantly higher with-the-rule (PT 1.72 $\pm 1.59 \mathrm{D}, \mathrm{NPT} 1.19 \pm 0.88 \mathrm{D}, \mathrm{p}<0.0001$ ) and against-the-rule (PT 1.63 $\pm 1.46 \mathrm{D}, \mathrm{NPT} 1.18 \pm 0.88 \mathrm{D}$, $\mathrm{p}<0.0001$ ) but similar oblique astigmatism (PT 1.11 $\pm 1.00 \mathrm{D}$, NPT $0.99 \pm 0.89 \mathrm{D}, \mathrm{p}=0.065$ ) corneal astigmatism compared with the NPT group. Power vector analysis indicated that the axis of corneal astigmatism was not significantly different between the two groups $\left(\mathrm{J}_{0}, \mathrm{PT}-0.01 \pm 0.74 \mathrm{D}\right.$, NPT $0.01 \pm 0.52 \mathrm{D}, \mathrm{p}=0.48 ; \mathrm{J}_{45}, \mathrm{PT}-0.03 \pm 0.82 \mathrm{D}$, NPT $0.00 \pm 0.52 \mathrm{D}, \mathrm{p}=0.54$ ).

Conclusions Pattern of corneal astigmatism in eyes with cataract and coexisting primary pterygium was different from eyes without pterygium. Pterygium is associated with higher magnitude but not different axis of corneal astigmatism.

\section{INTRODUCTION}

Cataract surgery is the only effective treatment proven for age-related cataract. In cataract surgery, accurate assessment of axial length, corneal power and anterior chamber

\section{Strengths and limitations of this study}

- The present study investigated the distribution of corneal astigmatism in cataract eyes with primary pterygium in a rural Chinese population.

- The study consisted of a large sample size to reveal the change of corneal astigmatism in eyes with primary pterygium.

- The study was limited by its single-centre and retrospective design.

- The timing of pterygium surgery in cataract eyes needs to be further investigated.

depth is crucial to achieve satisfactory visual function and reduce spectacle dependence postoperatively. ${ }^{12}$ Corneal astigmatism is also one of the major factors affecting postoperative visual function. ${ }^{2}$ With the increasing demand of surgery for patients with cataract and surgeons for better postoperative visual quality, proper and precise management of preoperative corneal astigmatism is one of the key issues for a successful and satisfactory cataract surgery. At tropical areas where people have long time exposure to ultraviolet light, eyes with age-related cataract are often accompanied by coexisting pterygium. ${ }^{4}$ Pterygium have been shown to cause corneal irregularity and corneal astigmatism. ${ }^{5} 6$ Proper management of corneal astigmatism in cataract eyes with coexisting pterygium may be challenging to cataract surgeons and it requires the knowledge about the distribution of corneal astigmatism in these eyes. The purpose of the present study was to investigate the distribution of corneal astigmatism in cataract eyes with primary pterygium in a southern Chinese population.

\section{MATERIALS AND METHODS \\ Participants}

This is a retrospective study approved by the Institutional Review Board of Shanwei Eye 
Hospital and is in agreement with the Declaration of Helsinki. Medical records of eyes referred for cataract surgery between 2014 and 2016 were reviewed and eyes meeting inclusion criteria were included consecutively. A total of 1689 cataract eyes with pterygium and 4062 cataract eyes without pterygium were identified preoperatively for analysis. Inclusion criteria were age-related cataract with or without coexisting primary pterygium. Exclusion criteria were eyes with pseudopterygium, recurrent pterygium, corneal dystrophy or corneal degeneration, history of corneal infection, glaucoma, uveitis, ocular trauma or ocular surgery. Eyes with large pterygium (exceeded $3 \mathrm{~mm}$ into the cornea) and/or in which keratometry could not be performed were also excluded. Since only review of medical records was conducted and no individual patient could be identified from the data, informed consent was waived.

Eyes were divided into two groups on the basis of with or without pterygium: pterygium group (PT) and no pterygium group (NPT), and they were further stratified into five groups based on age 50-59 years, 60-69 years, $70-79$ years, $80-89$ years and 90 years and older. All of the eyes underwent cataract surgery (cataract surgery alone, simultaneous/sequel pterygium and cataract surgery) after thorough preoperative examination.

\section{Examination}

A comprehensive ocular examination was performed on every patient, including best corrective visual acuity, intraocular pressure with non-contact tonometry (CT-60; Topcon), slit lamp examination and dilated pupil for lens and fundus examination. Corneal power was measured by an autokeratorefractometer (KR-8900, Topcon, Tokyo, Japan) by experienced technicians. The patient's head was positioned in front of the autokeratorefractometer with the forehead and chin properly aligned and supported, and both lateral canthi aligned with the marks. The patient was asked to blink several times to have the tear film evenly distributed on the cornea. The patient was asked to open the eye and stare at the fixation target while the autokeratorefractometer was proceeded to the cornea. Once image of the pupil was clearly shown on the centre of the display, the measurement button was pressed and three consecutive corneal curvature measurements were taken automatically. The procedure was performed again if the patient's eye blink during the measurements or if agreement of the three measurements was poor. The average of the three measurements with good agreement was recorded.

Corneal astigmatism was calculated as the difference in corneal power between the steepest and flattest meridians. Corneal astigmatism was defined as with-the-rule (WTR) when the steepest meridian was $90^{\circ} \pm 30^{\circ}$, as against-therule (ATR) when the steepest corneal meridian was between $1^{\circ}$ and $30^{\circ}$ or between $150^{\circ}$ and $180^{\circ}$ and as oblique astigmatism (OBL) when the steepest meridian was $>30^{\circ}$ and $<60^{\circ}$ or $>120^{\circ}$ and $<150^{\circ}$.

\section{Power vector analysis}

Since corneal astigmatism is a vector consisting both magnitude and axis, power vector analysis was used to evaluate the corneal astigmatism in the eyes included, according to the following equations ${ }^{8}$ :

$$
\begin{aligned}
& \mathrm{J}_{0}=-\mathrm{C} / 2 * \cos 2 \alpha \\
& \mathrm{J}_{45}=-\mathrm{C} / 2 * \sin 2 \alpha
\end{aligned}
$$

where $\mathrm{C}$ is minus astigmatism power and $\alpha$ is minus astigmatism axis. $\mathrm{J}_{0}$ indicates orthogonal cylinder power set at $90^{\circ}$ and $180^{\circ}$, and is a positive value in WTR astigmatism and a negative value in ATR astigmatism. $\mathrm{J}_{45}$ indicates OBL at $45^{\circ}$ and $135^{\circ}$, and is positive when the positive cylinder is closer to $135^{\circ}$ and is negative when it is closer to $45^{\circ} .7$

\section{Patient and public involvement}

There was no patient or public involvement in the development and design of the study.

\section{Statistical analysis}

Statistical analysis was performed using STATA software (V.15.0, sStata, Inc). Kolmogorov-Smirnov test was used to evaluate normality of all variables. Data of corneal astigmatism were presented as mean \pm SD. $\chi^{2}$ test or Fisher's exact test was used to compare proportional data. Twotailed Student's t-test was used for comparison of data with normal distribution and a Mann-Whitney $\mathrm{U}$ test for other distributions. $\mathrm{P}<0.05$ was considered to be statistically significant.

\section{RESULTS}

The study included a group of 1689 eyes with primary pterygium (PT group) and the other group of 4062 eyes without pterygium (NPT group). The basic characteristics and spectrum of corneal astigmatism in the PT group and NPT group are presented in table 1.

Distribution of age groups and gender was not significantly different between the PT group and the NPT group (both $\mathrm{p}>0.05$, figure $1 \mathrm{~A}, \mathrm{~B}$ ). Distribution of corneal astigmatism was different between the PT group (skewness $=2.548$, kurtosis $=8.237$, figure $2 \mathrm{~A}$ ) and the NPT group (skewness=2.778, kurtosis $=15.52$, figure 2B). Corneal astigmatism distribution of the PT group was more positively skewed and strongly peaked than the NPT group. Mean corneal astigmatism was significantly higher in the PT group $(1.62 \pm 1.49 \mathrm{D})$ compared with the NPT group $(1.17 \pm 0.89 \mathrm{D}, \mathrm{p}<0.0001)$. In the PT group, corneal astigmatism was $\leq 1.0 \mathrm{D}$ in $47.7 \%, 1.0-2.0 \mathrm{D}$ in $29.8 \%, 2.0-3.0 \mathrm{D}$ in $11.9 \%$ and $>3.0 \mathrm{D}$ in $10.5 \%$ of eyes. In the NPT group, corneal astigmatism was $\leq 1.0 \mathrm{D}$ in $59.1 \%, 1.0-2.0 \mathrm{D}$ in $30.4 \%, 2.0-3.0 \mathrm{D}$ in $7.4 \%$ and $>3.0 \mathrm{D}$ in $3.2 \%$ of eyes ( $<<0.001$ compared with the PT group). The prevalence of corneal astigmatism >1D (PT 52.3\%, NPT 40.9\%, $\mathrm{p}<0.0001),>2 \mathrm{D}$ (PT 22.4\%, NPT 10.6\%, $\mathrm{p}<0.0001$ ) or $>3$ D (PT 10.5\%, NPT 3.2\%, p $<0.0001)$ was significantly 
Table 1 The frequency and demographic characteristic between patients with and without pterygium (mean $\pm S D$ )

\begin{tabular}{llll}
\hline Parameter & $\begin{array}{l}\text { Eyes with } \\
\text { pterygium }\end{array}$ & $\begin{array}{l}\text { Eyes without } \\
\text { pterygium }\end{array}$ & P value \\
\hline $\begin{array}{l}\text { Number of } \\
\text { eyes }\end{array}$ & 1689 & 4062 & \\
WTR, eyes & $705(41.7 \%)$ & $1698(41.8 \%)$ & $0.966^{\star}$
\end{tabular}

(\%)

\begin{tabular}{lccc}
$\begin{array}{l}\text { ATR, eyes } \\
(\%)\end{array}$ & $834(49.4 \%)$ & $2046(50.4 \%)$ & $0.494^{*}$ \\
\hline $\begin{array}{l}\text { OBL, eyes } \\
(\%)\end{array}$ & $150(8.9 \%)$ & $318(7.8 \%)$ & $0.184^{*}$
\end{tabular}

(\%)

\begin{tabular}{lclc} 
Age (years) & $71.4 \pm 8.1$ & $70.3 \pm 8.5$ & $<0.001 \dagger$ \\
$\begin{array}{l}\text { Male/female } \\
\text { sex (\%) }\end{array}$ & $47.4 \% / 52.6 \%$ & $50.6 \% / 49.4 \%$ & $0.023^{*}$ \\
$\begin{array}{l}\text { Corneal } \\
\text { astigmatism }\end{array}$ & $1.62 \pm 1.49$ & $1.17 \pm 0.89$ & $<0.001 \dagger$ \\
(D) & & & \\
WTR (D) & $1.72 \pm 1.59$ & $1.19 \pm 0.88$ & $<0.001 \dagger$ \\
ATR (D) & $1.63 \pm 1.46$ & $1.18 \pm 0.88$ & $<0.001 \dagger$ \\
OBL (D) & $1.11 \pm 1.00$ & $0.99 \pm 0.89$ & $0.065 \dagger$ \\
\hline J0 (D) & $-0.01 \pm 0.74$ & $0.01 \pm 0.52$ & 0.480 \\
\hline J45 (D) & $-0.03 \pm 0.82$ & $0.00 \pm 0.52$ & 0.540 \\
\hline
\end{tabular}

${ }^{*} \chi^{2}$ test, $p<0.05$ was considered to be statistically significant. †Mann-Whitney test, $p<0.05$ was considered to be statistically significant.

ATR, against-the-rule; D, diopter; OBL, oblique astigmatism; WTR, with-the-rule.

higher in the PT group compared with the NPT group. Moreover, eyes in the PT group had significantly higher corneal astigmatism than the NPT group in almost every age group (all $p<0.05$ ), with the exception of patients $\geq 90$ years (figure 3 ).

In the PT group, corneal astigmatism was WTR in $41.7 \%$, ATR in $49.4 \%$ and OBL in $8.9 \%$ of eyes. In the NPT

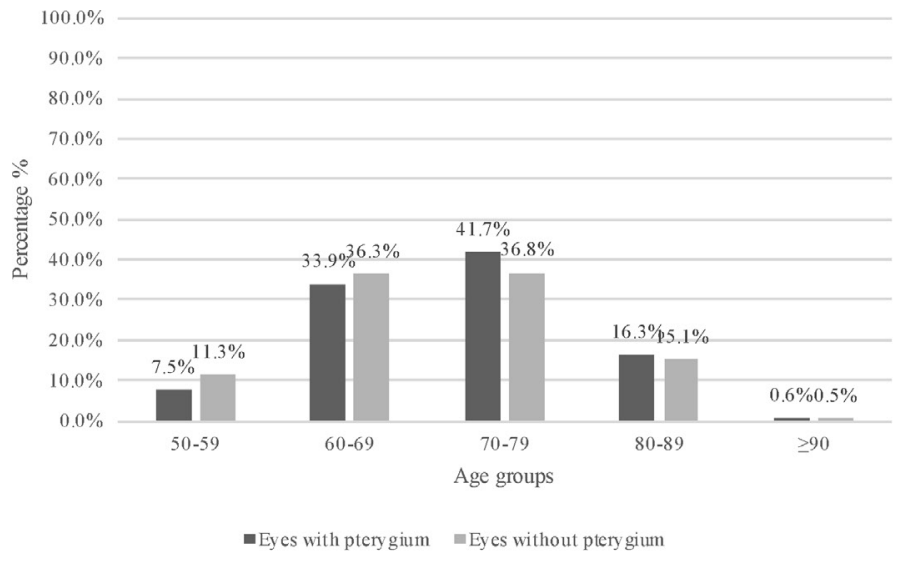

A group, corneal astigmatism was WTR in $41.8 \%$, ATR in $50.4 \%$ and OBL in $7.8 \%$ of eyes $(p=0.391$ compared with the PT group, figure 4). Eyes in the PT group had significantly higher WTR (PT 1.72 $\pm 1.59 \mathrm{D}$, NPT $1.19 \pm 0.88 \mathrm{D}$, $\mathrm{p}<0.0001$ ) and ATR (PT 1.63 $\pm 1.46 \mathrm{D}$, NPT $1.18 \pm 0.88 \mathrm{D}$, $\mathrm{p}<0.0001$ ) but similar OBL (PT 1.11 $\pm 1.00 \mathrm{D}$, NPT $1.00 \pm 0.89 \mathrm{D}, \mathrm{p}=0.065)$ corneal astigmatism compared with the NPT group (figure 5). Power vector analysis indicated that the axis of corneal astigmatism was not significantly different between the two groups $\left(\mathrm{J}_{0}, \mathrm{PT}-0.01 \pm 0.74 \mathrm{D}\right.$, NPT $0.01 \pm 0.52 \mathrm{D}, \mathrm{p}=0.48 ; \mathrm{J}_{45}$, PT $-0.03 \pm 0.82 \mathrm{D}$, NPT $0.00 \pm 0.52 \mathrm{D}, \mathrm{p}=0.54$, figure 6 ).

\section{DISCUSSIONS}

Pterygium is an ocular surface disorder involving a winglike fibrovascular growth of the bulbar conjunctiva and underlying subconjunctival tissue onto the cornea. ${ }^{9}$ It is commonly seen in areas within the 'pterygium zone'-a geographical latitude $40^{\circ}$ north and south of the equator, ${ }^{10}$ and in people with outdoor occupations or hobbies, ${ }^{9} 10$ implicating the role of UV radiation in the pathogenesis of pterygium. Besides, chronic irritation and/or inflammation in the peripheral cornea and limbus caused by dust, low humidity, microtrauma from smoke or sand, human papilloma virus infection and genetic factors have also been suggested as risk factors for the development of pterygium. ${ }^{9}$ Pterygium has been found to have a significant impact on the corneal surface, reducing corneal surface regularity index while increasing astigmatism and the surface asymmetry index. ${ }^{56}$ It has been shown that corneal astigmatism is significantly higher in eyes with pterygium compared with eyes without pterygium, ${ }^{11}$ and that pterygium-induced astigmatism is associated with size and vascularity index of the pterygiam. ${ }^{5}$ MohammadSalih and Sharif analysed corneal astigmatism in 77 patients with unilateral primary pterygium and showed that the mean difference in corneal astigmatism between pterygium-affected eyes and control eyes was $0.60 \pm 0.7 \mathrm{D}$.

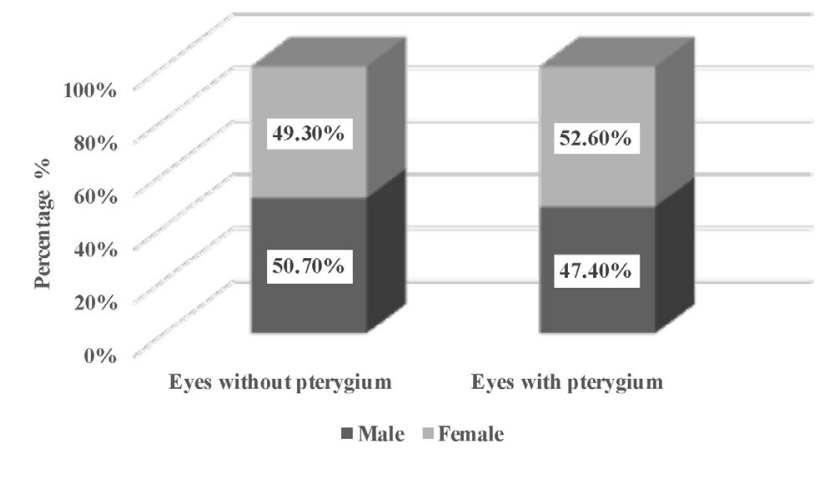

B

Figure 1 Frequency distribution (\%) of eyes with or without pterygium by age group (A) and frequency distribution (\%) of eyes with or without pterygium by gender group (B). 


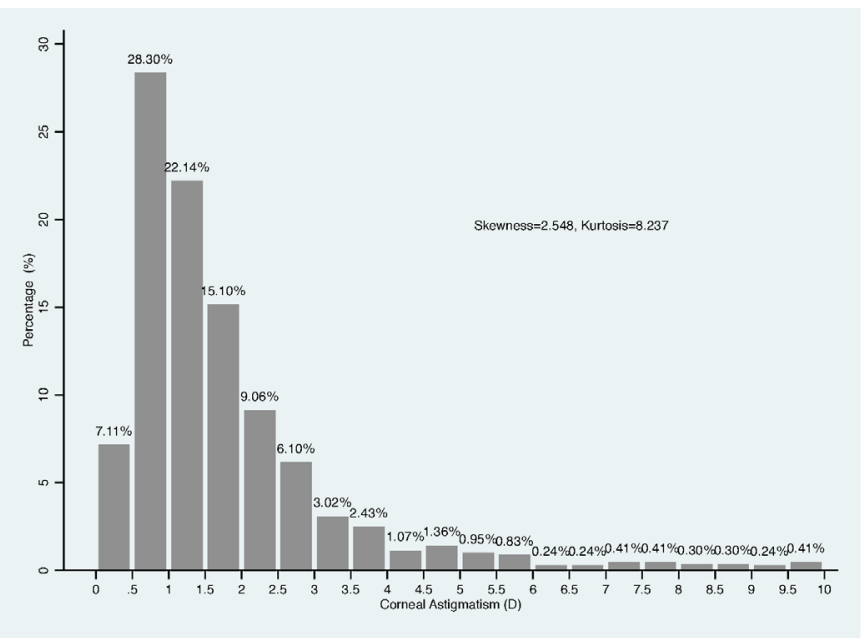

A

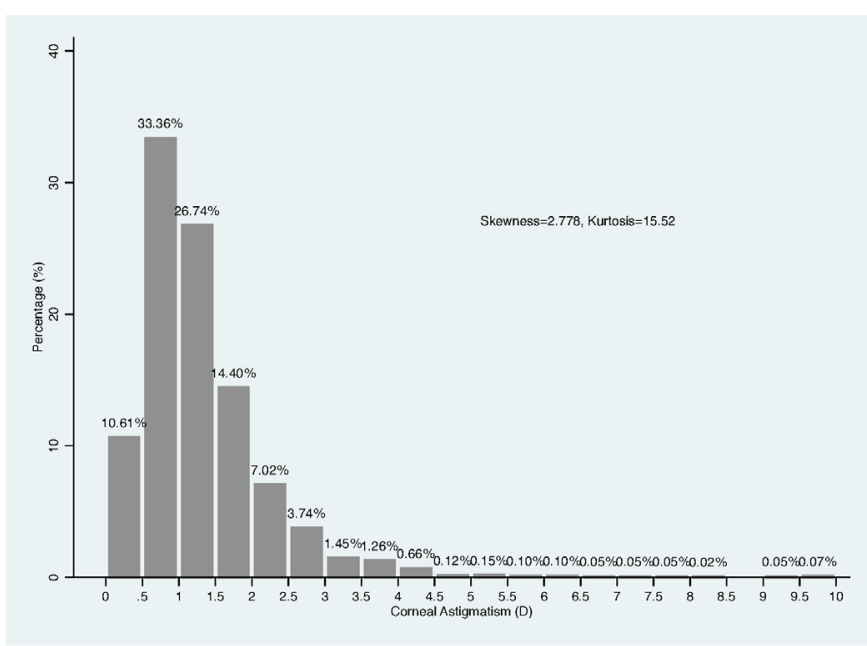

B

Figure 2 Frequency distribution (\%) of corneal astigmatism in eyes with pterygium (A) and eyes without pterygium (B).

They also found a positive linear correlation between pterygium size and corneal astigmatism. ${ }^{11}$ In a consecutive series of 163 eyes undergoing primary pterygium removal surgery, percent pterygium extension was positively correlated with preoperative corneal astigmatism and postoperative change in corneal astigmatism. ${ }^{12}$ In our study, cataract eyes with pterygium were found to have significant higher corneal astigmatism $(1.62 \pm 1.49 \mathrm{D})$ than those without pterygium $(1.17 \pm 0.89 \mathrm{D}, \mathrm{p}<0.001)$. Mean corneal astigmatism in the PT group was also significantly higher than the corneal astigmatism reported in eyes without pterygium from other Chinese populations. ${ }^{13-15}$ The difference in mean corneal astigmatism between the PT group and NPT group was 0.45D. This was consistent with what had been reported in the literature. ${ }^{511} 12$
In the era of precision medicine, proper management of corneal astigmatism has become increasingly important in cataract surgery. With the increasing demand of postoperative visual quality, accurate preoperative evaluation of corneal astigmatism and precise intraoperative astigmatism correction are crucial in patients undergoing cataract surgery, ${ }^{16}$ especially for patients with pterygium, in whom the pterygium may affect the corneal astigmatism and its management strategy. A fundamental basis of precision astigmatism management in cataract eyes with pterygium is the knowledge about distribution and change of corneal astigmatism in these eyes. In the present study, we showed that the distribution of corneal astigmatism in cataract eyes with pterygium was different from eyes without pterygium. The distribution curve of

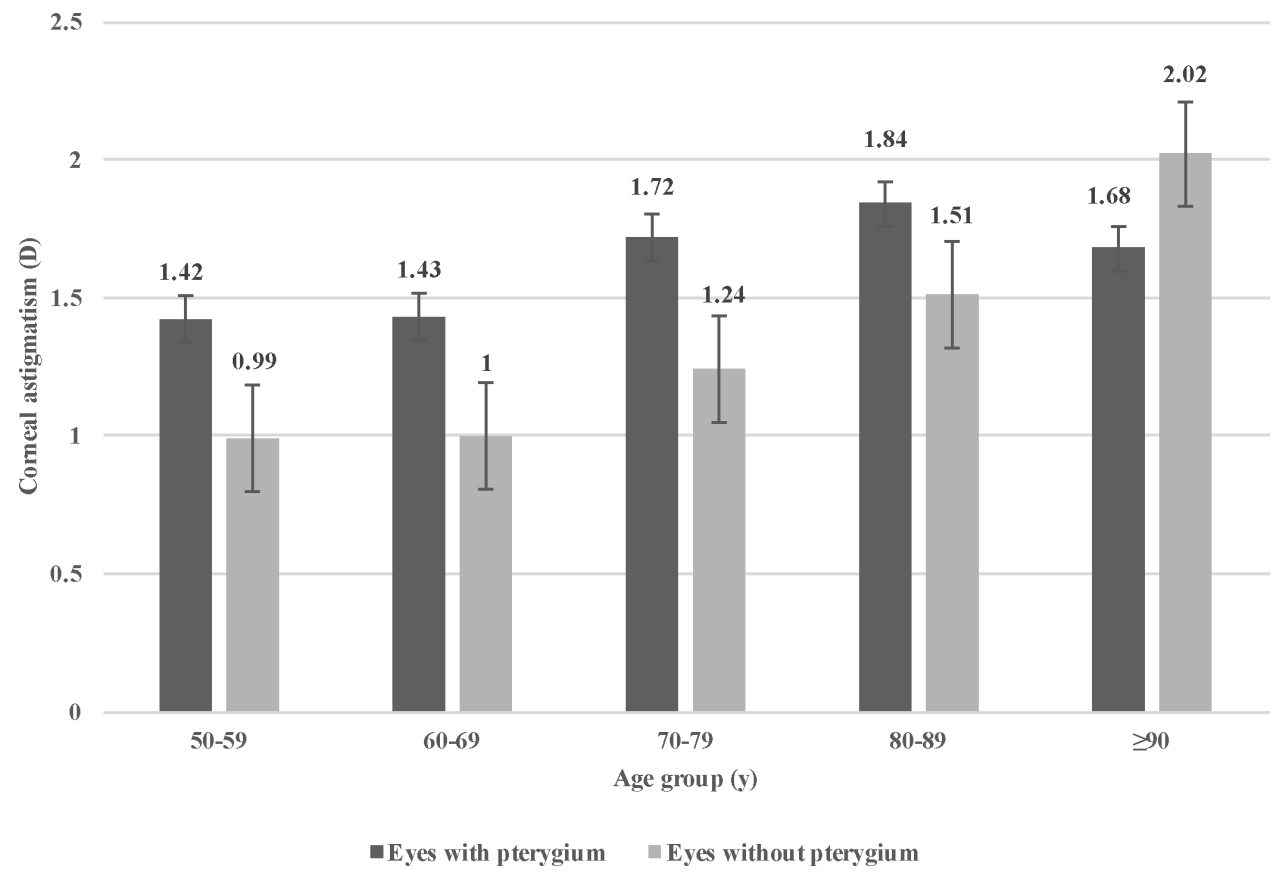

Figure 3 Magnitude of corneal astigmatism (D) in five age groups. 


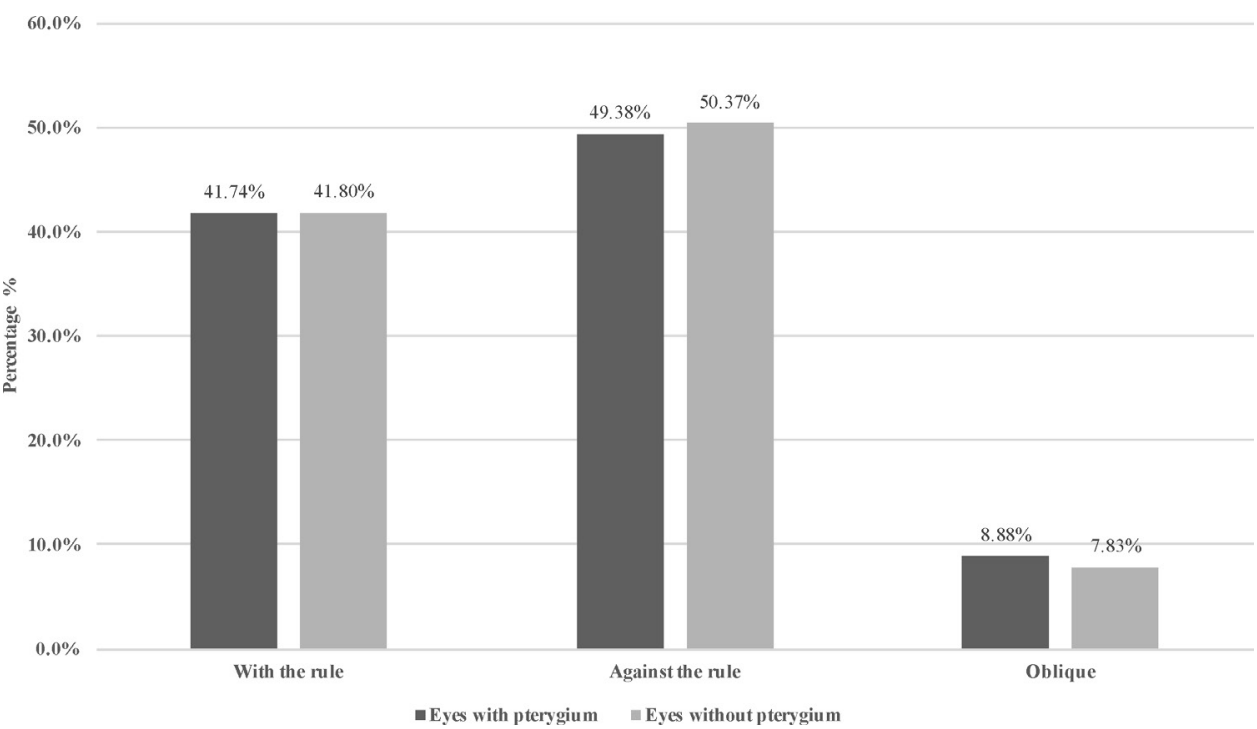

Figure 4 Frequency distribution (\%) of with-the-rule, against-the-rule and oblique astigmatism in eyes with or without pterygium.

corneal astigmatism in the PT group was less positively skewed and lower peaked than the NPT group. It meant that higher prevalence of larger corneal astigmatism was present in the PT group compared with the NPT group. In our study, the mean WTR and ART corneal astigmatism were significantly higher in cataract eyes with pterygium compared with eyes without pterygium. These findings indicate that corneal astigmatism is higher in cataract eyes with primary pterygium and a high magnitude of astigmatism correction is needed to be considered in these eyes. Moreover, in patients having simultaneous pterygium and cataract surgery, the extra corneal astigmatism induced by the pterygium may need to be taken into account when deciding the intraocular lens (IOL) power. The corneal astigmatism was also significantly higher in cataract eyes with pterygium than eyes without pterygium in all the age groups, with the exception of patients $\geq 90$ years. The exception might be due to the small sample size in this age group. However, the trend of corneal astigmatism change in our study was consistent with a recent study by Shao et al that showed a non-linear trend of increased corneal astigmatism with ageing. ${ }^{17}$ Careful evaluation and management of the higher corneal astigmatism in cataract eyes with coexisting pterygium is crucial to having satisfactory visual outcomes after cataract surgery, especially in eyes with ATR corneal astigmatism.

In contrary to the common belief that pterygium could flatten the cornea on the horizontal axis and cause WTR, our study showed that the proportions of WTR, ATR and OBL were not significantly different between the PT and NPT groups. Power vector analysis also indicated that the axis of corneal astigmatism was not significantly different between the two groups. These findings suggest that in our population the pterygium may not be associated with change of corneal astigmatism axis in cataract eyes. Therefore, adjustment of target corneal astigmatism in these eyes should focus more on the magnitude but less on the orientation of the corneal astigmatism. Besides,

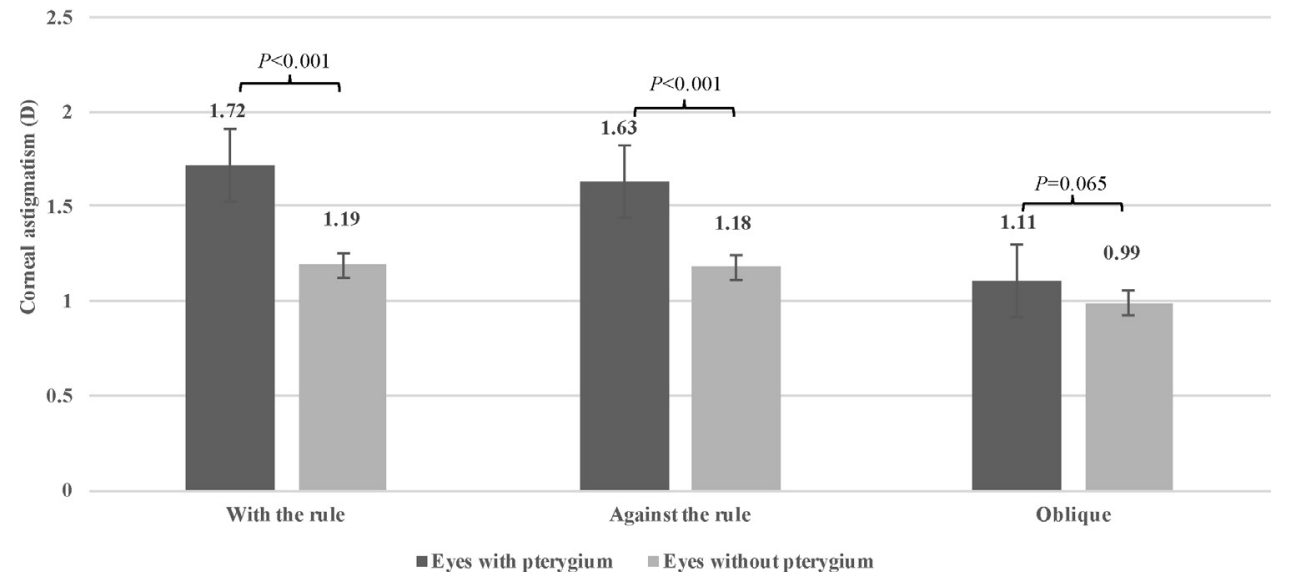

Figure 5 Magnitude of with-the-rule, against-the-rule and oblique corneal astigmatism (D) in eyes with or without pterygium. 


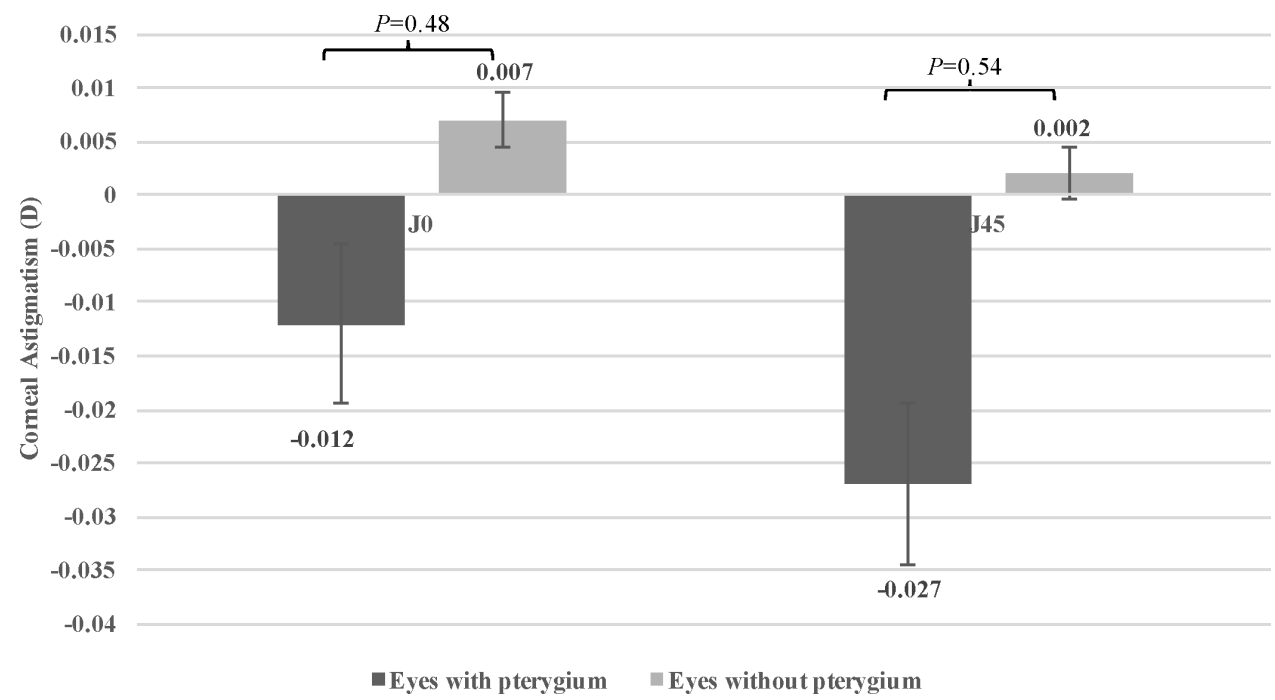

Figure 6 Power vector analysis of corneal astigmatism (D) in eyes with or without pterygium.

mean ATR corneal astigmatism was significantly higher in the PT group than the NPT group. These findings could be explained by the diversity of pterygium characteristics in our study, considering a large number of eyes with pterygium were included. Various characteristics of pterygium might have diverse effects on corneal astigmatism and subepithelial irregularities. ${ }^{18}$

Due to the corneal astigmatism caused by pterygium, eyes with cataract and coexisting pterygium usually need to undergo pterygium removal before cataract surgery can be performed, if the pterygium cause significant change in corneal astigmatism. Pujol et al showed that the best threshold of preoperative corneal astigmatism of indicating astigmatism reduction after pterygium surgery was $1.05 \mathrm{D}$, with $82.5 \%$ sensitivity and $80.5 \%$ specificity. ${ }^{19}$ After pterygium removal, the timing of cataract surgery also needs to be considered. Tomidokoro et al showed that refractive status of the cornea was markedly modified but stabilise 1 month after pterygium surgery, and have suggested cataract surgery to be performed 1 month or more after pterygium surgery. ${ }^{12}$ After pterygium surgery, the residual corneal astigmatism can be managed by limbal relaxing incisions, femtosecond laser-assisted astigmatic keratotomy or toric IOL implantation during cataract surgery. ${ }^{20}{ }^{21}$ One of the key issues to a sustainable visual outcome after subsequent cataract surgery is the prevention of pterygium recurrence. Surgical methods such as conjunctival autografting and conjunctive mitomycin $\mathrm{C}$ have been wildly used in pterygium surgery to minimise recurrence. ${ }^{22}{ }^{23}$ In some settings simultaneous pterygium excision and cataract surgery may be recommended to the patients to provide faster visual recovery while reducing hospital visits and overall cost. ${ }^{2425}$ In these patients, a postoperative myopic shift should be taken into account when deciding the IOL power when the pterygium is large. ${ }^{24} 25$

The study was limited by its single-centre and retrospective design. Since we only included eyes referred for cataract surgery, most of our patients were aged people. Many young patients with primary pterygium and eyes with pterygium but without cataract were not included. Therefore, the results of the study only reflected the effect of primary pterygium on corneal astigmatism observed in eyes with age-related cataract. Moreover, this is a crosssectional study, the cut-offs of corneal astigmatism and pterygium characteristics parameters indicating the benefit of pterygium removal in cataract eyes could not be determined. A prospective cohort study is needed to address these issues.

In conclusion, our study provides previously unavailable information regarding the details in distribution of corneal astigmatism in cataract eyes with coexisting pterygium. Change of corneal astigmatism in these eyes is an important clinical issue which cannot be overlooked during planning of cataract surgery.

Contributors $\mathrm{GX}$ and $\mathrm{YH}$ designed the study. WQ and $\mathrm{YH}$ collected the dada. GX and $\mathrm{YH}$ analysed and interpreted the data. $\mathrm{GX}$ and $\mathrm{YH}$ wrote the article. WQ and $\mathrm{YH}$ made critical revision to the article. All authors have read and approved the final version of the manuscript.

Funding This work was supported by the Science Research Foundation of Aier Eye Hospital Group (AF2018003) and the Science and Technology Planning Project of Shanwei City (2017C015). The study was designed, analysed and interpreted independent of funding sources.

Competing interests None declared.

Patient consent for publication Not required.

Ethics approval The study was in agreement with the Declaration of Helsinki and approved by the Institutional Review Board of Shanwei Eye Hospital.

Provenance and peer review Not commissioned; externally peer reviewed.

Data availability statement Data are available upon reasonable request.

Open access This is an open access article distributed in accordance with the Creative Commons Attribution Non Commercial (CC BY-NC 4.0) license, which permits others to distribute, remix, adapt, build upon this work noncommercially, and license their derivative works on different terms, provided the original work is properly cited, appropriate credit is given, any changes made indicated, and the use is non-commercial. See: http://creativecommons.org/ licenses/by-nc/4.0/.

ORCID iD

Yijun Hu http://orcid.org/0000-0002-6424-7905 


\section{REFERENCES}

1 Fotedar R, Wang JJ, Burlutsky G, et al. Distribution of axial length and ocular biometry measured using partial coherence laser interferometry (IOL master) in an older white population. Ophthalmology 2010;117:417-23.

2 Hoffmann PC, Hütz WW. Analysis of biometry and prevalence data for corneal astigmatism in 23,239 eyes. J Cataract Refract Surg 2010;36:1479-85.

3 Hayashi K, Manabe S-I, Yoshida M, et al. Effect of astigmatism on visual acuity in eyes with a diffractive multifocal intraocular lens. $J$ Cataract Refract Surg 2010;36:1323-9.

4 Pham TQ, Wang JJ, Rochtchina E, et al. Pterygium, pinguecula, and 5-year incidence of cataract. Am J Ophthalmol 2005;139:1126-8.

5 Han SB, Jeon HS, Kim M, et al. Quantification of astigmatism induced by pterygium using automated image analysis. Cornea 2016;35:370-6.

6 Minami K, Miyata K, Otani A, et al. Detection of increase in corneal irregularity due to pterygium using Fourier series harmonic analyses with multiple diameters. Jpn J Ophthalmol 2018;62:342-8.

7 Day AC, Dhariwal M, Keith MS, et al. Distribution of preoperative and postoperative astigmatism in a large population of patients undergoing cataract surgery in the UK. Br J Ophthalmol 2019;103:993-1000.

8 Thibos LN, Wheeler W, Horner D. Power vectors: an application of Fourier analysis to the description and statistical analysis of refractive error. Optom Vis Sci 1997;74:367-75.

9 Rezvan F, Khabazkhoob M, Hooshmand E, et al. Prevalence and risk factors of pterygium: a systematic review and meta-analysis. Surv Ophthalmol 2018;63:719-35.

10 Ang M, Li X, Wong W, et al. Prevalence of and racial differences in pterygium: a multiethnic population study in Asians. Ophthalmology 2012;119:1509-15.

11 Mohammad-Salih PA-K, Sharif AFMD. Analysis of pterygium size and induced corneal astigmatism. Cornea 2008;27:434-8.

12 Tomidokoro A, Miyata K, Sakaguchi Y, et al. Effects of pterygium on corneal spherical power and astigmatism. Ophthalmology 2000;107:1568-71.
13 Cui $\mathrm{Y}$, Meng Q, Guo H, et al. Biometry and corneal astigmatism in cataract surgery candidates from southern China. J Cataract Refract Surg 2014;40:1661-9.

14 Yuan X, Song H, Peng G, et al. Prevalence of corneal astigmatism in patients before cataract surgery in northern China. J Ophthalmol 2014;2014

15 Huang Q, Huang Y, Luo Q, et al. Ocular biometric characteristics of cataract patients in Western China. BMC Ophthalmol 2018;18:99.

16 Rubenstein JB, Raciti M. Approaches to corneal astigmatism in cataract surgery. Curr Opin Ophthalmol 2013;24:30-4.

17 Shao X, Zhou K-J, Pan A-P, et al. Age-Related changes in corneal astigmatism. J Refract Surg 2017;33:696-703.

18 Gasser T, Romano V, Seifarth C, et al. Morphometric characterisation of pterygium associated with corneal stromal scarring using highresolution anterior segment optical coherence tomography. $\mathrm{Br} J$ Ophthalmol 2017;101:660-4.

19 Pujol P, Julio G, de Carvalho AM, et al. Threshold to predict astigmatism reduction after pterygium excision. Optom Vis Sci 2014;91:747-51.

20 Roberts HW, Wagh VK, Sullivan DL, et al. Refractive outcomes after limbal relaxing incisions or femtosecond laser arcuate keratotomy to manage corneal astigmatism at the time of cataract surgery. $J$ Cataract Refract Surg 2018;44:955-63.

21 Kessel L, Andresen J, Tendal B, et al. Toric intraocular lenses in the correction of astigmatism during cataract surgery: a systematic review and meta-analysis. Ophthalmology 2016;123:275-86.

22 Fonseca EC, Rocha EM, Arruda GV. Comparison among adjuvant treatments for primary pterygium: a network meta-analysis. $\mathrm{Br} \mathrm{J}$ Ophthalmol 2018;102:748-56.

23 Kam KW, Kwok RPW, Belin MW, et al. Long-Term density changes in corneal layers after primary pterygium excision with topical mitomycin-C. Cornea 2016;35:1093-6.

24 Kamiya K, Shimizu K, lijima K, et al. Predictability of intraocular lens power calculation after simultaneous pterygium excision and cataract surgery. Medicine 2015;94:e2232.

25 Koc M, Uzel MM, Aydemir E, et al. Pterygium size and effect on intraocular lens power calculation. J Cataract Refract Surg 2016;42:1620-5. 